\title{
Responsa Rabínicos y Cartas Reales: fuentes para el estudio de la historia de los judíos en la Corona de Aragón
}

\author{
Yom Tov Assis *
}

Pocas comunidades medievales han sido tan afortunadas como las comunidades judías de la Península Ibérica en el caudal de fuentes existentes para el estudio de su historia. Estas fuentes permiten a los historiadores describir en gran detalle casi todos los aspectos del quehacer humano y analizar en profundidad diversos capítulos de la historia de la comunidad. El historiador de la judeidad española se encuentra con un problema especial: cómo hacer frente a esta abundancia de fuentes que despierta la envidia de los historiadores de otras comunidades medievales. Más aún, el estudio de la judeidad española debe no sólo ser selectivo al elegir las fuentes a citar o a exponer en su trabajo, sino debe decidir qué tipo de fuentes necesita usar en cada área particular de investigación. La variedad de fuentes permite al historiador, equipado con los instrumentos necesarios - lingüísticos, paleográficos y otros- tener una muy amplia perspectiva y una profunda visión de la vida de los judíos medievales en España.

El uso de fuentes hebreas y archivísticas en latín y en lenguas romance permite al historiador ver un cuadro de la vida judía en España mucho más cercano a la realidad histórica y mucho menos distorsionado y fragmentado que en los casos en que las fuentes no ofrecen esta posibilidad o el historiador no se vale de todas las categorías de fuentes ${ }^{1}$. En general,

* Universidad Hebrea de Jerusalén.

Sobre el uso de fuentes hebreas y archivísticas para el estudio de la historia judía véase Romano, D., "Responsa y repertorios documentales", Sefarad, n. ${ }^{\circ}$ XXVI, 1966, págs. 47-52; AsSIS, Y., "Los judíos de Cataluña: Fuentes y posibilidades trabajo», Actes Ir. Colloqui d'Història dels Jueus a la Corona d'Aragó. Lérida 1991, págs. 139-155. 
las fuentes hebreas de España, que consisten en obras de responsa, trabajos éticos, exegéticos, filosóficos y literarios, registros y ordenanzas comunitarios y libros de cuentas personales, son particularmente ricas. Este material ha sido escasamente usado por estudiosos españoles y, en algunos casos, no ha atraído suficiente a la atención de historiadores de otros países, incluyendo a Israel.

Las fuentes hebreas revelan aspectos de la vida judía que no podrían ser detectados desde afuera. La información que ofrecen emana de la comunidad judía y refleja tendencias y estados de ánimo que no pueden ser captados por un observador de afuera. Sus referencias a los intrincamientos de la ley y las costumbres judías eran ininteligibles para las autoridades no judías. Los argumentos legales y la base de las decisiones y los veredictos halájicos eran absolutamente extraños para todas las autoridades gentiles que tenían alguna conexión con los judíos. Las fuentes hebreas presentan una imagen íntima de la vida judía dentro de los límites de la judería que los extraños no podían haber captado. Por todas estas razones, su valor no puede ser menospreciado ${ }^{2}$.

Las fuentes hebreas solas, sin embargo, presentan sólo parte del cuadro. Son en su mayoría decisiones legales compuestas por algún experto en ley judía o registradas por alguno de sus discípulos. Los responsa pretendian principalmente, si no exclusivamente, servir como precedentes legales en las cortes judías. Consecuentemente, importantes detalles históricos a veces son omitidos. En muchos responsa los nombres de lugares y personas, cantidades de dinero y fechas han sido sustituidos por fórmulas y expresiones carentes de valor histórico. El caso tratado en un responsum pueden haber sido excepcional y lejos de ser representativo de una tendencia. Más aún, las compilaciones de responsa era generalmente copiadas muchas veces por copistas de diferentes países y épocas. El número de errores aumentaba en proporción con la popularidad de la colección específica. Con la introducción de la imprenta ese tipo de errores se difundieron y perpetuaron de edición en edición. Inclusive cuando se proporciona información precisa en un responsum, los copitas, al igual que los editores modernos, que no estaban familiarizados con el medio ambiente del autor e ignoraban el transfondo histórico, geográfico, económico, social y cultural, cometieron serios errores, a veces creyendo que corregían un texto corrupto ${ }^{3}$.

\footnotetext{
2 Sobre las responsa en general véase FREEHOF, S., The responsa hiterature. Philadelphia 1959; idem, A treasury of responsa. Philadelphia 1963; BAZAK, J. y PASSAMANEK, S., Jewish Law and Jewish life: Selected Rabbinical responsa. Cincinnati 1979.

3 Véase WeinRyb, B., "Responsa as a Source for History (Methodological Problems)", in
} 
Veamos un ejemplo. En 1959, Rabí Yosef Kapah publicó una edición crítica de los responsa de Ritba, Rabí Yom Tov ben Abraham Al-Ishbili, un importante halajista en la Corona de Aragón a comienzos del siglo XIV y discípulo de Rabí Shelomo ben Adret y Rabí Aharon Haleve de Na Cla$\mathrm{ra}^{4}$. El editor usó un antiguo manuscrito y lo copió en forma tan fiel como era humanamente posible. Sus correcciones de errores obvios se presentan en corchetes, mientras las palabras erradas están entre paréntesis. Cuando no está seguro, deja el texto sin modificar, pero sugiere una enmienda en una nota al pie o en su introducción. Responsum 114, por ejemplo, está dirigido a una localidad llamada En su introducción en la página 15, el editor sugiere que el lugar es aparentemente Lara, cerca de Burgos. No cabe duda que Lérida, en el oeste de Cataluña, es la versión correcta, y que la confusión entre la $T$ y la 7 se debió al hecho que el copista no conocía Lérida, al igual que el editor. En otro responsum la palabra abreviada 'w el editor a ${ }^{5}$. El editor no conocía aparentemente la palabra $\Delta \boldsymbol{u}$ ', que es «jaqueses", la moneda de Aragón, llamada solidi de Jaca - jaqueses, por la localidad de Jaca, donde se acuñaban las monedas.

A pesar de esas discrepancias, las fuentes hebreas son invalorables por diversas razones, inclusive en temas que se tratan en extenso en documentos de archivo en latín y en lenguas romance. Los libros de cuentas en hebreo contienen información que los protocolos notariales no proporcionan. La mayor colección de libros de cuentas privados judíos hallada hasta el momento en la Europa cristiana es de Navarra y se encuentra en el Archivo General de Navarra, en Pamplona. Conjuntamente con un colega he publicado parte del material en un libro hebreo sobre los judíos de Navarra y todos los libros se incluirán en un libro en castellano que está siendo publicado en España ${ }^{6}$. Los libros de cuentas son en hebreo o en aljamiado y revelan algunos detalles que muestran cuán engañosos pueden ser los protocolos notariales si se los emplea solos. La fuente en hebreo o aljamiado estaba destinada exclusivamente para uso privado y, por tanto, quien la escribía podía incluir información, que generalmente se ocultaba, de las autoridades y que podía ser incri-

Essay Presented to Chief Rabbi Israel Brodie. Londres 1967, págs. 399-417; SoloveITCHIK, H., Šeelot u-Tešubot ke-Maqor Histori. Jerusalén 1990.

4 R. Yom Tov ben Abraham Alasbill, Šeelot uTešubot, Y. Kapah ed. Jerusalén 1959 [=Alasbili].

Ibidem, págs. 15, 127, 114 y 191, n. ${ }^{\circ} 161$.

6 Assis, Y. y Magdalena, J. R., Yehude Navarra. Jerusalén 1990; idem, Navarra judaica, edición anotada de los documentos del Archivo General de Navarra. Pamplona 1992; idem, Aljamía romance en los documentos hebraiconavarros (siglo XN). Barcelona 1992. 
minadora. En un caso, el propietario del libro de cuentas declaró claramente que la suma registrada en el notario era más alta que el préstamo real $^{7}$. Esto significa que la tasa de interés era más alta que lo determinado en el registro notarial.

La poesía y otras obras literarias hebreas revelan, además, detalles de la vida judía que no siempre se obtienen en fuentes cristianas. Estas fuentes nos permiten penetrar profundamente en la vida judía y nos presentan estados de ánimo y sentimientos, tendencias y pensamientos que prevalecían en la sociedad judía. La poesía de Todros Halevi Abulafia describe vívidamente el estilo de vida de las clases altas en la sociedad judía. Sus poemas contradicen descripciones de la sociedad judía halladas en algunas obras éticas o polémicas, e inclusive halájicas ${ }^{8}$. Por ejemplo, el elogio de Yosef Qimhi a las virtudes de las doncellas judías es absolutamente engañoso y no puede ser aceptado en su sentido literal $^{9}$. El hecho de que los poemas de amor mundano de los judíos españoles no son más que imaginativos ejercicios literarios, está implícito en las idealizadas narraciones sobre los altos patrones morales de los judíos y la auto-contención que se encuentran en los textos judíos medievales. El «Elogio a Dios por la pureza de las generaciones en estas regiones, en las que las doncellas judías son modestas y observan los mandamientos sin elegir a sus esposos sin el consentimiento de su padre», es una vasta generalización incompatible con la atmósfera general que prevalecía en la sociedad judeo-española ${ }^{10}$. Los responsa mismos de Adret contienen suficiente evidencia para demostrar que la sociedad judía estaba lejos de ser homogénea. La poesía de Abulafia, los sermones de Todros Halevi Abulafia, el homónimo del poeta, y numerosas otras fuentes hebreas, indican que en la sociedad judeo-española el relajo sexual y moral era un problema real que afectaba a grandes sectores ${ }^{11}$. Las fuentes en latín y lenguas romances añaden detalles que son vitales para una imagen comprensiva de la vida judía en la España medieval.

\footnotetext{
7 Véase, por ejemplo, Assis y Magdalena, Yehude Navarra, doc. 4, cap. 8, líneas 21-24; idem, Navarra Judaica, e idem, Aljamia romance, doc. 10, fol. 4 v. ${ }^{\circ}$, líneas 21-24.

s Véase Diwan of Todros son of Yehuda Abu-l-Afiah Gan Hammeshalim we-hahidoth, ed. D. Yellin, 2 partes, 3 vols. Jerusalén 1932, 1934, 1936; BAER, Y., "Todros ben Yehuda Halevi uZemano", Zion, n. ${ }^{\circ}$ II, 1937, págs. 19-55; idem. Historia de los judíos en la España cristiana, trad. por J. L. Lacave, I. Madrid 1981, págs. 190-192.

${ }_{9}$ Yosef QIMHI, R., Sefer ha-Berit u-Vikuhe RaDaQ im ha-Noșrim. Jerusalén, Ed. E. Talmage. 1974, pág. 26.

10 R. Śelomo ben AdRet, Šeelot u-Tešubot. Bolonia 1539, n. ${ }^{\circ} 1219$ [=Adre I].

$"$ Véase Assıs, Y., "Peša' va-Alimut ba-Hebrah ha-Yehudit bi-Sefarad (Meot 13 \& 14)", Zion Jubilee Volume, 1985, págs. 221-240; idem, «Sexual behaviour in Mediaeval Hispano-Jewish society", Jewish history, essays in honour of Chimen Abramsy, Ed. A. Rapoport-Albert \& S. J. Zipperstein. Londres 1988, págs. 25-59.
} 
Las polémicas religiosas internas y las actividades sociales difícilmente podrían ser estudiadas sin fuentes judías. En las fuentes cristianas prácticamente no hay referencias a las agrias polémicas que dividieron a las comunidades judías en la Península Ibérica.

Los documentos en latín y romance usualmente nos proporcionan detalles que no se encuentran en fuentes paralelas. Nombres de personas y de lugares, fechas y precios, se hallan en documentos de archivo de las cancillerías reales o de notarios. La política judía del monarca puede ser estudiada únicamente en base a la documentación de la Cancillería Real. Los impuestos judíos pueden ser evaluados y analizados únicamente con las fuentes oficiales preservadas en los archivos. Ninguna actividad económica de los judíos puede ser estudiada apropiadamente sin los protocolos notariales y el material de los archivos reales. Los archivos municipales arrojan luz sobre las relaciones entre la comunidad judía y la municipalidad cristiana y sobre la actitud de ésta hacia los judíos locales. El estudio de las actividades de la Inquisición es inconcebible sin los protocolos de los juicios inquisitoriales, mientras el retorno de los conversos al judaísmo no puede ser investigado sin los responsa pertinentes.

La historia de ninguna comunidad medieval puede ser narrada en su totalidad, porque carecemos de mucha información que nunca fue escrita por la vasta población silenciosa que no sabía leer ni escribir. Ni siquiera los más ricos registros contienen los pensamientos y sentimientos de las masas judías. Cualquier descripción de su conducta cotidiana y de sus actividades económicas, de sus prácticas religiosas y de su vida familiar se infiere necesariamente de fuentes indirectas. De una manera general, las fuentes a nuestra disposición reflejan la vida de los judíos de las clases altas. Esta falta, por sí sola, es suficiente para que todo historiador preste mayor atención al hecho que ninguna categoría de fuentes puede ser descuidada o ignorada. Porque, de otro modo, el cuadro puede ser aún más distorsionado y reducido.

En este trabajo deseo demostrar la vital necesidad de hacer uso de todas las fuentes existentes y la dependencia mutua de las fuentes judías y no judías para lograr una comprensión adecuada de los eventos y de la información histórica en la perspectiva más amplia posible. La ausencia de información de un tipo de fuentes distorsiona o, en el mejor de los casos, cambia seriamente el significado, la naturaleza y el peso de los acontecimientos y afecta al carácter y al alcance de nuestro conocimiento histórico. En muchos temas y episodios, el uso de diferentes tipos de fuentes nos permite ver un cuadro más completo. Por medio de fuentes, que fueron escritas originalmente para diferentes propósitos y desde diversos ángulos, podemos comprender y apreciar el tema tratado. 
Examinemos uno de los más fascinantes episodios en la historia de los judíos del siglo xIII en Aragón. Lo haremos usando los responsa de R. Salomon ben Adret y documentos del Archivo de la Corona de Aragón, específicamente las Cartas Reales encontradas en la sección de la Cancillería Real. Los responsa de Adret son la colección más rica de España; más de 3.000 responsa impresos, y muchos otros en manuscrito, contienen valiosa información sobre la vida judía en la Península Ibérica y, particularmente, en las comunidades de la Corona de Aragón. R. Salomon ben Abraham ben Adret, el más importante halajista en el último cuarto del siglo XIII y la primera década del siglo XIV, vivió en Barcelona, donde enseñaba a muchos discípulos. Perles y Epstein escribieron sobre él en base a sus propios trabajos y los de sus discípulos ${ }^{12}$. De acuerdo a documentos del Archivo Capitular de Barcelona, su nombre era Adret y no Aderet como erróneamente se creía en muchos círculos judíos. De no haber sido por documentos de este archivo, parte de los cuales publiqué en el primer volumen de la serie «Fuentes para la Historia de los Judíos en España», no sabríamos que, por lo menos hasta 1277, Adret prestaba dinero y firmaba su nombre en hebreo en pagarés. Su actividad de prestamista, conocida sólo de los documentos latinos, es de gran importancia para el estudio de la historia del rabinato en España ${ }^{13}$. Las prominentes autoridades rabínicas en España no se ganaban la vida como rabinos, sino trabajaban en muchas áreas y profesiones. Las actividades de prestamista de Adret demuestran, además, la actitud de las autoridades halájicas en España hacia el préstamo de dinero a interés.

Las Cartas Reales, que fueron erróneamente llamadas en el pasado Reales Diplomáticas, forman una colección extremadamente rica de la correspondencia real con cada persona y cada institución. Por una parte, la serie contiene las cartas del rey enviadas a sus destinatarios y que de algún modo encontraron su camino al archivo o cartas escritas y nunca despachadas por una u otra razón, y por otra parte, cartas enviadas al rey por funcionarios o cualquier persona. Las cartas del rey eran generalmente copiadas, antes de su despacho, en registros que constituyen la más rica sección del archivo. La cantidad de estos documentos, que se refieren a judíos y a comunidades judías, es inmensa y versan sobre

12 Perles, J., R. Salomo b. Abraham b. Adreth: sein Leben und seine Schriften. Breslau 1863; EPSTEIN, I., The Responsa of R. Solomon ben Adreth of Barelona (1235-1310) as a source of the history of Spain. Londres 1925.

13 CinTA MAÑE, M., The Jews in Barcelona 1213-1291, Regesta of documents from the Archivo Capitular, docs. $168,177,182,184,193-4,200,205,209,215-6,239-40,248,254-5,259$, 271, 277, 279, 283, 285, 288-9, 327, Jerusalén Ed. Y. Assis. 1988. 
Responsa Rabínicos y Cartas Reales: fuentes para el estudio de la historia..

todos los aspectos de la vida. Examinaremos los eventos que tuvieron lugar en Aragón, usando documentos del Archivo de la Corona de Aragón y responsa de Adret.

En 1263 estalló un serio conflicto en Zaragoza, la capital de Aragón ${ }^{14}$. El transfondo de la crisis que dividió a la comunidad judía de Zaragoza fue social y económico. La crisis se extendió a otras comunidades en el noreste de la Península y extremeció las bases de la estructura social y del régimen comunitario en las aljamas. Su rápida difusión demuestra que el problema era general y estaba profundamente arraigado. En 1263, judíos miembros de las clases bajas en Zaragoza se dirigieron al baile a quien persuadieron de modificar el sistema impositivo a favor del sistema llamado per solidum et libram. Este sistema era apoyado por los pobres, dado que se basaba en la propia declaración del contribuyente respecto a sus ingresos y propiedades, hecha bajo juramento. Bajo el otro método, apoyado por los ricos, los tasadores de impuestos, designados por los líderes de la comunidad y consecuentemente representantes de los intereses de las clases altas, determinaban la cantidad de impuestos que cada miembro de la comunidad debía pagar. La suma total que la comunidad de Zaragoza debía pagar era determinada sin importar el método empleado. En principio, por tanto, el rey no tenía preferencia por ninguno de ellos.

La más temprana información sobre el episodio se encuentra en fuentes hebreas y latinas. Las fuentes hebreas no divulgan la identidad del baile de Zaragoza, llamado guizbar en hebreo; de fuentes latinas sabemos que el baile entre 1257 y 1276 fue el famoso judío de Zaragoza Yehuda ben Lavi de la Cavallería, un prominente miembro de la comunidad y uno de los más notables funcionarios de Jaime $\mathrm{I}^{15}$. De una fuente latina entendemos que la queja al baile provino de judíos pobres que sentían que la administración rica les imponía impuestos injustos. La fuente hebrea, sin embargo, nos cuenta que los judíos pobres en Zaragoza formaron un movimiento político dentro de la comunidad que pretendía introducir cambios radicales en su régimen. La fuente judía nos da el nombre del movimiento como es decir, la Fracción Popular. De los responsa de Adret queda en claro que precedió a la queja al baile una agitación social ${ }^{16}$. Puede parecer asombroso que el baile Yehuda de la

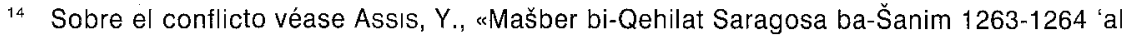
pi Meqorot 'Ibriyim ve-Lo'aziyim», Proceedings of the 7th World Congress of Jewish Studies, History of the Jews in Europe. Jerusalén 1981, págs. 37-42.

15 Bofarull. y Sans, F. de, Los judíos en el territorio de Barcelona (siglos x al xili). Reinado de Jaime 1. Barcelona 1910, págs. 17-20; VENRELL GallostrA, F., «Aportaciones para el estudio de la familia Caballería», Sefarad, n. III, 1943, págs. 118-119.

${ }_{16}$ R. ŠELOMO bEN AdRET, Šeelot u-Tešubot. Leghorn 1778, n. 394 [=Adret III]. 
Cavallería, que pertenecía a las clases ricas, prestara oído a las quejas de los pobres contra los ricos, líderes de la aljama. La explicación puede radicar en los deseos de Yehuda de contener las ambiciones de su rival Alconstantini, cuyas demandas y aspiraciones le enojaban mucho. Parece, casi seguro, que uno de sus principales objetivos, al apoyar a los pobres de su comunidad, fue bloquear el continuo ascenso de la familia Alconstantini. La rivalidad entre ambas familias está bien documentada en fuentes de archivo.

Los ricos de Zaragoza no aceptaron los espectaculares logros de los pobres. Los adelantados de la comunidad que representaban a las familias acomodadas enviaron delegados a un lugar llamado Landaa ( $ה \times ד>$ ( - Lardaa ( $(\pi \times T 3 \times 3)$ ), de acuerdo a los textos impresos de los responsa de Adret sobre el asunto. ¿Dónde y cuándo tuvo lugar el encuentro con Jaime I? Las fuentes hebreas no brindan ninguna respuesta. El lugar, arriba mencionado, es desconocido. Parece improbable que el rey haya estado en ese lugar. La fuente hebrea no contiene ningún dato. El nombre de la localidad sufrió corrupciones a manos de copistas que nunca oyeron de la ciudad de Lérida, en el oeste de Cataluña, en la frontera con Aragón. El encuentro de los delegados con Jaime I se llevó a cabo en Lérida entre el 3 y 12 de septiembre de 1263. Ésos fueron los únicos días en que Jaime I permaneció en Lérida desde fines de junio de 1263 hasta el 4 de agosto de $1264^{17}$.

Los representantes de los ricos lograron éxito en su misión, después de ofrecer al rey un generoso «soborno»; así, exactamente, describe la fuente hebrea el pago ${ }^{18}$. De hecho, el encuentro del rey con los representantes no se menciona de ningún modo en las fuentes archivísticas. Uno de los cinco privilegios, que los ricos obtuvieron de Jaime I, cancelaba la anterior promesa del rey a los pobres de cambiar el sistema de impuestos. Los líderes de los pobres, que dirigieron la oposición a la comunidad, son anónimos en las fuentes hebreas, mientras la fuente latina nos proporciona sus nombres completos ${ }^{19}$. Para los acomodados de la comunidad su logro no fue suficiente; de acuerdo a una fuente hebrea los líderes de la aljama exigieron que los pobres también pagaran su parte del dinero pagado al rey por los delegados de los ricos. Esta demanda enfureció naturalmente a los miembros de la «Fracción Popular».

17 Véase Archivo de la Corona de Aragón [=A.C.A.], Cancillería, Reg. 12-14 y Libre dels feyts, en F. Soldevilla (ed.), Les Quatre Grans Croniques. Barcelona 1971.

Adret III, n. ${ }^{\circ} 402$.

19 A.C.A., Reg. 12, fol. 144. 
Responsa Rabínicos y Cartas Reales: fuentes para el estudio de la historia...

A pesar del éxito de los ricos, el proceso que había empezado con la organización de la sa no pudo ser detenido. Los representantes de los pobres siguieron ocupando sus posiciones en la administración ${ }^{20}$. Aquí, las fuentes latinas son indispensables. Nombran a los tasadores de impuestos y a los miembros de otras instituciones comunitarias. Fue bajo la presión de las clases más pobres que la comunidad de Zaragoza emitó en ese tiempo una ordenanza, prohibiendo a todo judío solicitar exención - reducción de impuestos. La ordenanza se encuentra en uno de los responsa de Adret. Era válida por cincuenta años ${ }^{21}$. Hasta entonces, el rey otorgaba exenciones de ese tipo a los judíos. Los adelantados, que se opusieron a esto, fueron destituidos de sus puestos.

La ordenanza amenazaba con una severa multa y la excomunicación a cualquiera que actuara contra ella. En uno de los responsa de Adret se nos relata sobre una viuda y sus dos hijos huérfanos que obtuvo reducción, a pesar de la ordenanza antes mencionada. Se presentó una queja formal al bet din y la cuestión fue planteada a Adret, después de la decisión favorable de los adelantados. En el responsum de Adret no hay ninguna clave para indentificar a la viuda y a los dos huérfanos. Según el mismo responsum la viuda y sus hijos pertenecían a una prominente famila, cuya contribución a la aljama fue muy grande. La fuente en latín es muy engañosa, porque da la impresión de que la dura ordenanza actúa contra una pobre viuda y sus dos desafortunados hijos. La misma fuente proporciona la fecha, los nombres de la madre y de sus dos hijos. La madre era Oro, la viuda de Jacob Avinbaruch, y sus dos hijos eran Jucef y Salomon ${ }^{22}$. La familia Ibn Baruch era una prominente familia acomodada de Zaragoza y ni la viuda ni los dos huérfanos eran dignos de compasión. Los dos huérfanos eran dos hombres grandes que gozaban de fortuna y de poder. La reducción, ciertamente, no les fue otorgada por sus pobres condiciones. Muchos judíos de Zaragoza, especialmente miembros de las clases más pobres, tenían toda la razón para estar enojados con el impertinente intento de la familia Ibn Baruch de violar la ordenanza comunitaria.

La reacción de los pobres fue fuerte e, inclusive, violenta. El asesinato de Salomon ibn Baruch en 1284, registrado sólo en documentos latinos, estuvo indudablemente relacionado con la agitación que había caracterizado a la vida judía en Zaragoza durante los últimos veinte años. Iróni-

20 A.C.A., Reg. 12, fol. 148 [=F. Baer, Die Juden im christlichen Spanien, I, Urkunden un Regesten, Aragonien und Navarra. Berlín 1929, n. 198 [=Baer].

21 R. ŠElomo ben AdRET, Šeelot u-Tešubot. Leghorn 1825, n. 279 [=Adret V].

22 A.C.A., Reg. 12, fol. 151 r\&v [=Baer 99]. 
camente, Salomon, que había sido acusado de violar la ordenanza en 1264, fue asesinado después de haber sido nombrado por Pedro III para servir como dayán, juez, en la aljama ${ }^{23}$. Las fuentes hebreas no dicen nada sobre la continuación de la lucha y la rivalidad que existía entre las familias Alconstantini y Cavallería en los años setenta del siglo XIII. Después de la muerte de Yehuda de la Cavallería, Mosse Alconstantini fue nombrado baile de Zaragoza. Mosse inició inmediatamente procesos contra la aljama que había dictado la ordenanza contra los ricos que obtenían exención de impuestos del rey ${ }^{24}$. En 1280, Pedro III canceló todas las exenciones y reinstituyó el sistema de declaración, tan apoyado por los pobres ${ }^{25}$. El conflicto entre las clases en la comunidad de Zaragoza continuó durante muchos años. En la segunda década del siglo XIV, ricos y pobres aún luchaban, según indican fuentes latinas y hebreas. El autor de Livnat Hasapir, refiriéndose a los años 1324-1325, escribe: «Gracias a Dios que nos mostró gran misericordia y canceló Su severo juicio y concluyó el conflicto en la comunidad de Zaragoza» ${ }^{26}$.

Otro episodio de Aragón puede quedar más en claro con la ayuda de fuentes hebreas y latinas y por medio de su estudio comparativo. En el curso de la Edad Media, los judíos de la Europa Cristiana pasaron a ser cada vez más dependientes de los reyes y príncipes que los consideraban como su propiedad. Hacia el siglo XIII se empleaban términos especiales para denotar esta relación. La opinión del rey sobre el status de los judíos no es una cuestión teórica o de principio, porque era el rey quien determinába el status de los judíos y no la Iglesia, cuyo punto de vista sobre la posición de los judíos siguió como una doctrina sin importancia práctica, a pesar de su influencia a largo plazo en el concepto general de los judíos medievales en el mundo cristiano. En todos los países cristianos, los judíos se encontraban eventualmente bajo directa jurisdicción de los gobernantes; pasaban a ser parte de su tesoro y patrimonio, con todas las ventajas y desventajas que eso implica. La opinión de los judíos sobre su propio status puede haber sido un asunto para consuelo personal o imagen propia, pero no tenía ninguna consecuencia en la realidad. Así, las palabras de un estudioso judío del siglo xIv en Cataluña en cuanto a que «los judíos en todos sus asentamientos son hombres libres que pueden ir adónde deseen" no tienen ninguna base en la realidad ${ }^{27}$. La can-

23 BAER 127; RÉGnÉ, J., History of the Jews in Aragon, Documents and Regesta, 1213-1327, $\mathrm{n}^{\circ}{ }^{\text {s }} 1.118,1.128,1.143,1.144,1.176,1.192,1.224,1.234,1.235,1.354$ [= Régné]. Jerusalén 1978.

24 A.C.A., Reg. 41, fol. 6 [=Baer 114, 1]

25 A.C.A., Reg. 48, fol. 94 [=Régné 816]

26 Libnat ha-Sapir. Jerusalén 1913, fol. 65 v.

27 BAER 224a. 
Responsa Rabínicos y Cartas Reales: fuentes para el estudio de la historia...

tidad de libertad de movimiento de la que gozaban dependía totalmente de los deseos del rey. Más reflejaba la realidad la declaración del rey respecto a que los judíos eran «tesoro nuestro». Es comprensible, por tanto, que los reyes, que deseaban aumentar sus bienes, apoyaban la continua presencia e inclusive el aumento de la población judía dentro de su dominio, mientras los judíos fueran considerados un bien.

A lo largo de Europa, incluyendo los reinos cristianos en la Península Ibérica, los judíos pasaron a ser una importante fuente de ingresos reales. En Castilla y en la Corona de Aragón, los judíos fueron, además, usados en muchos terrenos relacionados con la Reconquista. En la Corona de Aragón, el grado en que los reyes Jaime I y Pedro III usaron a los judíos en la administración de sus dominios confederales no tiene paralelo en la Europa Cristiana. Las posiciones que los judíos ocuparon al servicio de la Corona eran en detrimento de la nobleza cristiana y el alto clero. Las tensas relaciones que existían entre los judíos y la nobleza al respecto se mejoraron en el momento en que fue retirada la causa. En 1283, Pedro III accedió a las demandas de las clases altas y destituyó a sus funcionarios judíos. Los judíos no constituyeron más un rival político para los nobles.

El interés de la nobleza en atraer pobladores judíos a sus dominios era esencialmente el mismo que el de la Corona. Los nobles ofrecían atractivas condiciones a los judíos que se establecieran en sus territorios y frecuentemente obtenían el permiso del rey para tener un número limitado de familias judías. Lo mismo fue hecho por algunos infantes. Tenemos también casos de migración judía en el sentido opuesto, de los dominios de la baronía a los reales. En todos los casos se ofrecían a los judíos buenas condiciones. En algunos casos, la emigración de judíos del dominio real era realizada sin el conocimiento o la autorización del rey o de la comunidad.

El rey no siempre sufría por esta emigración, porque el monto del impuesto que pagaba la comunidad en la Corona de Aragón permanecía estable. No era tal el caso de la comunidad, que debía asumir la misma carga, teniendo menos miembros entre quienes repartirla.

Las fuentes hebreas contienen información sobre la emigración de judíos de dominios reales a baronías. Esta información arroja una luz adicional al problema y revela algunos aspectos que afectan a la comunidad judía. La aljama, de la cual provenían los pobladores judíos del dominio de la baronía, se oponía enfáticamente a este movimiento de sus miembros. Esta oposición, en principio, fue debatida en círculos rabínicos. ¿Puede un judío ser restringido en sus movimientos? ¿Es su status frente a la comunidad similar al de un sujeto cristiano ante su señor? Ya nos 
hemos referido a la opinión de un estudioso rabínico de Cataluña del siglo XIV que denunció algunos intentos por parte de la comunidad para restringir la libertad de movimiento de sus miembros. El problema en discusión ocurrió a mediados del siglo xIV, cuando un judío y su familia, que había vivido en el territorio de un noble cerca de Gerona, decidió establecerse en Perpignan, donde la comunidad les ofrecía favorables condiciones para el pago de impuestos. Previamente habían pagado sus impuesto con la colecta de Gerona, dado que su hogar se encontraba dentro de sus límites, y pretendían pagar todas sus deudas, hasta el día en que abandonaran el lugar, transfiriendo sus pertenencias a Perpignan. Los líderes de la colecta, llamada en la fuente hebrea $n{ }^{2} \Omega$, es decir arca, trataron de evitar el traslado de la familia y evitar la pérdida financiera. La cuestión que se planteó fue si la comunidad tenía el derecho a forzar a un judío a permanecer bajo su jurisdicción. El alcance de la emigración de Cataluña a Roussillon no queda claro de la fuente hebrea, la cuestión fue planteada por Cresques Elies.

Una fuente latina de 1340 brinda una mejor apreciación de la situación. Las comunidades judías del reino se quejaron ante Pedro IV por la gran cantidad de miembros que habían emigrado y les habían causado un serio problema financiero. El rey era muy consciente de que la pérdida financiera de los judíos era también la suya, y por tanto, ordenó que se adoptaran ciertas medidas ${ }^{28}$.

El asunto ya había causado considerables problemas a las comunidades judías en el siglo XIII. Muchas comunidades emitieron ordenanzas, prohibiendo que los miembros abandonaran sin pagar todos sus impuestos retrasados. Zaragoza, por ejemplo, promulgó una ordenanza así; la emigración de judíos de Zaragoza a las aldeas pertenecientes a los nobles era lo suficientemente grande como para despertar preocupación en la aljama. Cuando la emigración continuó, a pesar de la ordenanza, la comunidad envió a Adret el texto de la ordenanza y detalles respecto a quienes la habían violado. ${ }^{29}$. Los emigrantes trasladaron su residencia a メงแาง , un lugar que no podemos identificar sin la ayuda de fuentes latinas. El nombre del señor también se desconoce en el responsum hebreo. En abril de 1292, la aljama de Zaragoza pidió a Jaime II obligar a todos los judíos que habían abandonado sus hogares en la ciudad y se habían establecido en los territorios de nobles aragoneses, particularmente Lope Ferrench de Luna, señor de Pedrola, a pagar sus impuestos

\footnotetext{
A.C.A., Reg. 1.056, fol. 89; Baer, pág. 316.

29 Adret III, n. 421.
} 
y deudas a la comunidad. La aljama estaba autorizada a excomunicarlos y se ordenó a las comunidades judías, en las que los emigrantes residían ahora, cumplir con la excomunicación ${ }^{30}$. De echo, una fuente de 1302 nos cuenta sobre judíos que habían traslado su hogar de Zaragoza a Pedrola y fueron arrestados por el merino de Zaragoza. Jaime II ordenó la liberación de esos judíos, Secrin Cadaix y Mahir de Roda ${ }^{31}$. No puede haber duda alguna de que el texto hebreo está corrupto y que el nombre correcto es Pedrola. El señor de Pedrola era Lope Ferrench de Luna, quien había sido autorizado por Alfonso III a establecer judíos en su dominio. En base a este privilegio, Lope Ferrench pudo obligar a algunos de «sus judíos» que habían abandona Pedrola y se habían establecido en Zaragoza y Alagón a regresar a su aldea ${ }^{32}$. Según una fuente en latín de 1305, Jaime II permitió a judíos que habían abandonado Alagón para establecerse en la baronía regresar a Alagón con sus efectos ${ }^{33}$. Sólo cuando leemos tanto las fuentes hebreas como las latinas empezamos a entender la naturaleza y el alcance del problema. Vemos cómo las comunidades de Zaragoza y Alagón trataron, no siempre con éxito, de atraer nuevamente a los judíos que se habían ido anteriormente a Pedrola y a otros dominios de la baronía. Ni su ordenanza ni sus términos favorables podían superar el acuerdo alcanzado entre Jaime II y Lope Ferrench y otros nobles. Sólo cuando el rey decidió modificar su política respecto al establecimiento judío en territorios de baronías se solucionó, al parecer, el problema.

Otro ejemplo que ilustra bien la interdependencia de las fuentes judías y no judías es la venta de propiedades judías. En la segunda mitad del siglo xIII y la primera mitad del siglo XIV, las comunidades judías en Aragón y Cataluña decidieron regular la venta de propiedades de sus miembros. El problema que trataban de solucionar eran los frecuentes reclamos de propiedades vendidas que surgían después de la transacción. Los compradores eran colocados en una situación muy embarazosa. Algurias comunidades decretaron que toda venta de propiedad debía ser anunciada públicamente en la sinagoga antes de pasar a ser válida. De acuerdo a la ordenanza emitida en varias comunidades, el demandante debía presentar su reclamo dentro de un período limitado desde el anuncio en la sinagoga. Después de este período no se podía aceptar reclamos. Las

30 A.C.A., Reg. 92 , fols. $31 \mathrm{v}-32$.

31 A.C.A., Reg. 199, fol. 79v [=Régné 2778]

32 A.C.A., Reg. 199, fol. 85 [=Régné 2780]

${ }^{33}$ A.C.A., Cartas Reales, Jaime II, caj. 17, n. ${ }^{\circ} 2147$. 
aljamas de Zaragoza ${ }^{34}$, Huesca ${ }^{35}$, Lérida ${ }^{36}$ y Monzón ${ }^{37}$ se contaron entre aquellas que promulgaron ordenanzas de este tipo. La ordenanza variaba de comunidad en comunidad, de acuerdo a las necesidades y deseos locales; en Zaragoza, la proclamación en la sinagoga era repetida durante cuatro sábados consecutivos, a petición del comprador ${ }^{38}$.

Las fuentes latinas de este período proporcionan más detalles sobre los problemas cotidianos relacionados con la transferencia y venta de bienes inmuebles y nos permiten comprender mejor la necesidad que llevó a varias comunidades aragonesas a dictar esas ordenanzas.

El tiempo y el espacio a nuestra disposición no nos permiten elaborar más sobre el tema en discusión. Creemos, sin embargo, que los casos mencionados prueban nuestra afirmación. El uso de todos los tipos de fuentes obtenibles es vital para la comprensión adecuada y para la perspectiva de los eventos históricos de nuestro estudio: la Historia de los Judíos en la Corona de Aragón.

34 Alasbili, n.. ${ }^{o s} 50,156$. R. Yishaq ben Šešet Perfet, Šeelot u-Tešubot. Lvov 1805, n. ${ }^{\text {os } 388-}$ $390[=$ Perfet $]$.

${ }_{35}$ R. Šelomo ben Adret, Šeelot u-Tešubot. Vilna 1881, n. ${ }^{\circ} 142$ [=Adret IV]; Adret III, n. ${ }^{\circ} 414$ [=Perfet 388].

${ }^{36}$ Adret III, n. ${ }^{\circ} 431 ; 1, n .{ }^{\circ} 893$.

${ }^{37}$ Adret III, n. ${ }^{\circ} 403$.

${ }_{38}$ SHILO, S., "ÁlŠte Taqanot Qahal bi-Sefarad», Sinai, n. LXI, 1957, págs. 291-292. 